Supporting Information:

\title{
Quantifying the Impact of Nanoparticle Coatings and Non-uniformities on XPS Analysis: Gold/silver Core-shell Nanoparticles
}

\author{
Yung-Cheng Wang, ${ }^{a}$ Mark. H. Engelhard, ${ }^{\mathrm{b}}$ Donald R. Baer ${ }^{\mathrm{b}}$ and David G. Castner ${ }^{\star \mathrm{a}, \mathrm{c}}$
}

${ }^{a}$ National ESCA \& Surface Analysis Center for Biomedical Problems, Department of Bioengineering, Box 351653, University of Washington, Seattle, WA 98195-1653 USA

\footnotetext{
${ }^{b}$ Environmental Molecular Sciences Laboratory, Pacific Northwest National Laboratory, Box 999, Richland WA 99352
}

'National ESCA \& Surface Analysis Center for Biomedical Problems, Department of Chemical Engineering, Box 351653, University of Washington, Seattle, WA 98195-1653 USA 


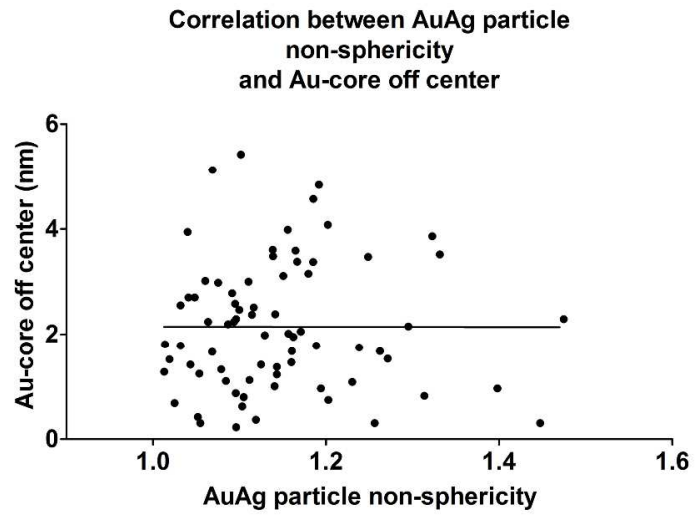

Figure S1. No linear correlation was found between the AuAg particle non-sphericity and Au-core off center $\left(R\right.$ square $\left.=1.3^{*} 10^{-6}\right)$.

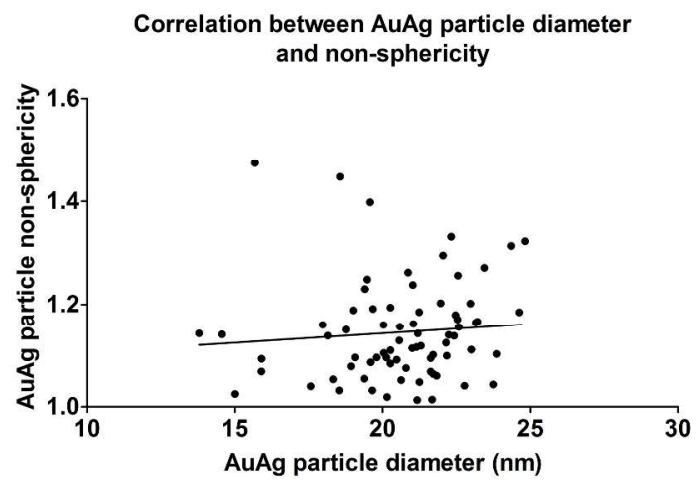

Figure S2. No linear correlation was found between the AuAg particle non-sphericity and Au-Ag particle diameter ( $R$ square $=0.0060$ ).

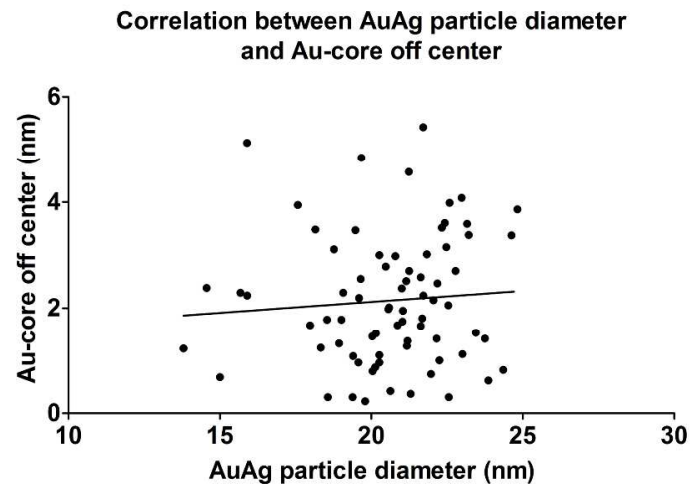

Figure S3. No linear correlation was found between the AuAg particle diameter and Au-core off center ( $R$ square $=0.0076)$. 


\begin{tabular}{|c|c|c|c|c|c|c|c|c|}
\hline \multirow{3}{*}{$\begin{array}{c}\text { hydrocarbon } \\
\text { thickness }(\mathrm{nm})\end{array}$} & \multicolumn{4}{|c|}{ ¿RMSD of one wash Au/Ag-core/shell NPs } & \multicolumn{4}{|c|}{ ¿RMSD of two wash Au/Ag-core/shell NPs } \\
\hline & \multicolumn{4}{|c|}{ Sodium citrate layer thickness $(\mathrm{nm})$} & \multicolumn{4}{|c|}{ Sodium citrate layer thickness (nm) } \\
\hline & $0.6 \mathrm{~nm}$ & $0.7 \mathrm{~nm}$ & $0.8 \mathrm{~nm}$ & $0.9 \mathrm{~nm}$ & $0.6 \mathrm{~nm}$ & $0.7 \mathrm{~nm}$ & $0.8 \mathrm{~nm}$ & $0.9 \mathrm{~nm}$ \\
\hline 0 & 6.00 & 3.84 & 2.03 & 1.45 & 4.48 & 2.42 & 1.31 & 2.33 \\
\hline 0.025 & 5.34 & 3.14 & 1.18 & 1.12 & 3.79 & 1.62 & 0.85 & 2.51 \\
\hline 0.05 & 4.85 & 2.57 & 0.73 & 1.27 & 3.29 & 1.05 & 1.08 & 2.77 \\
\hline 0.075 & 4.38 & 2.20 & 0.97 & 1.86 & 2.87 & 1.00 & 1.74 & 3.31 \\
\hline 0.1 & 3.99 & 2.12 & 1.59 & 2.58 & 2.64 & 1.53 & 2.49 & 3.96 \\
\hline
\end{tabular}

Table S1. 2 RMSD of experimental XPS result and SESSSA simulations by varying both sodium citrate layer thickness and hydrocarbon contamination layer thickness for the one wash and two wash samples. The lowest $\Sigma$ RMSD value indicates the combination of the two layers that gives the best fit to the experimental XPS result.

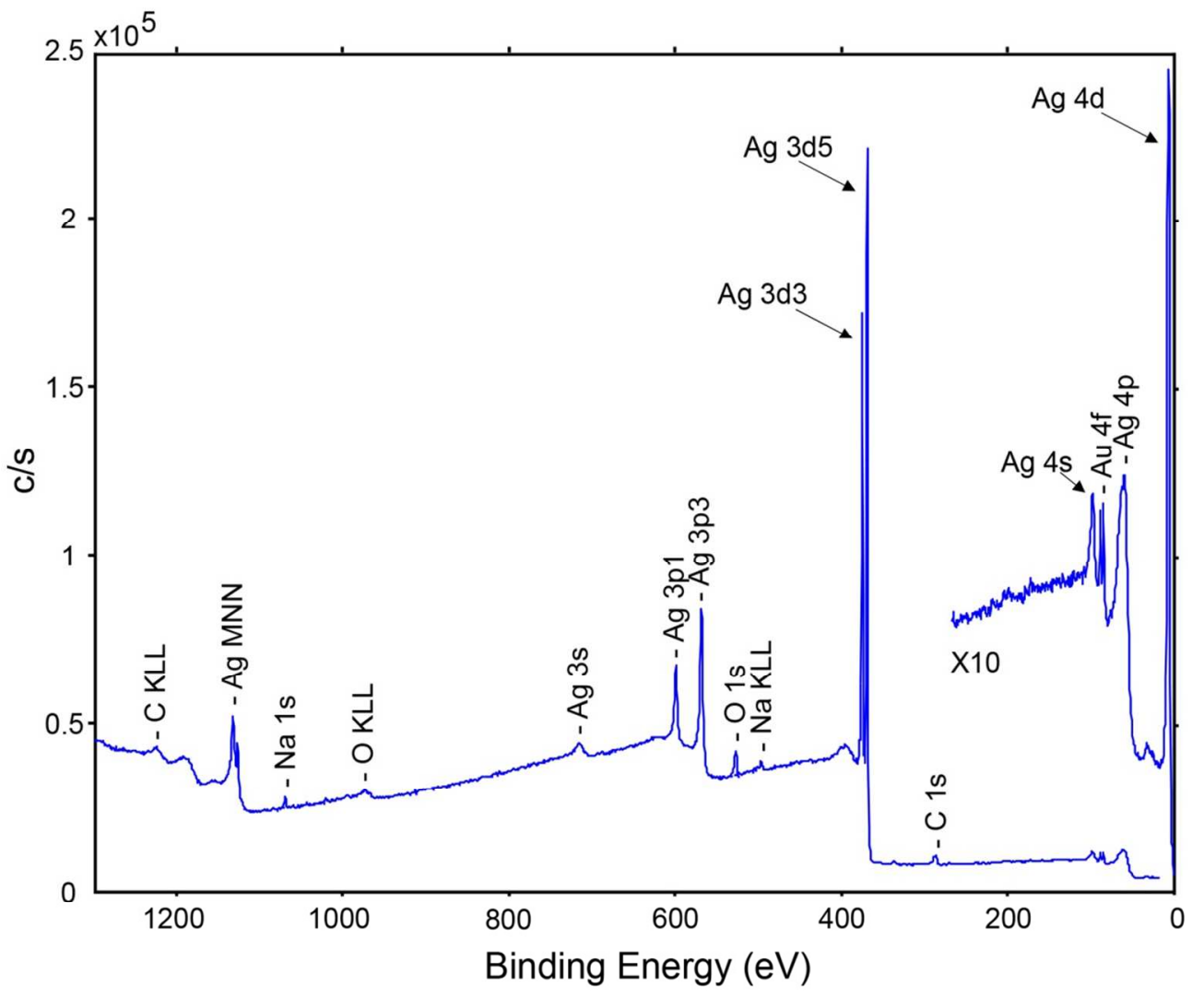

Figure S4. XPS survey spectra from Au/Ag-core/shell nanoparticles after one wash. All peaks identified in the spectrum can be associated with sodium citrate, the silver shells and a small amount of adventitious carbon contamination. As noted in Table 1, the compositions measured by XPS after wash 1 and wash 2 were very similar. 
$288.0 \mathrm{eV} 285.1 \mathrm{eV}$
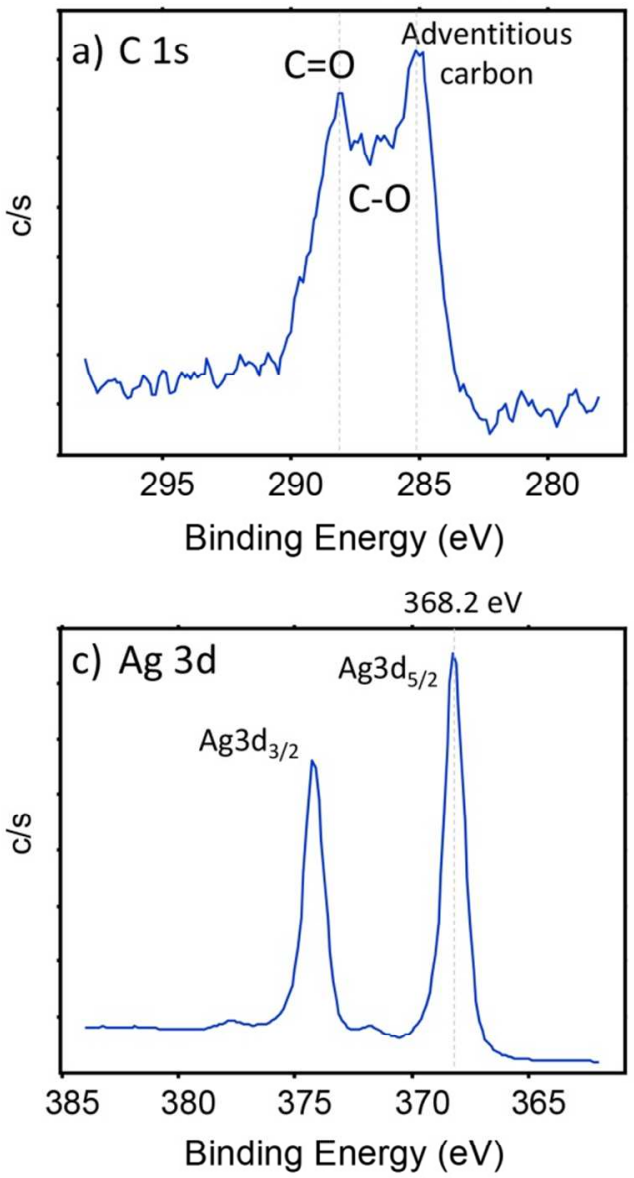

$531.4 \mathrm{eV}$

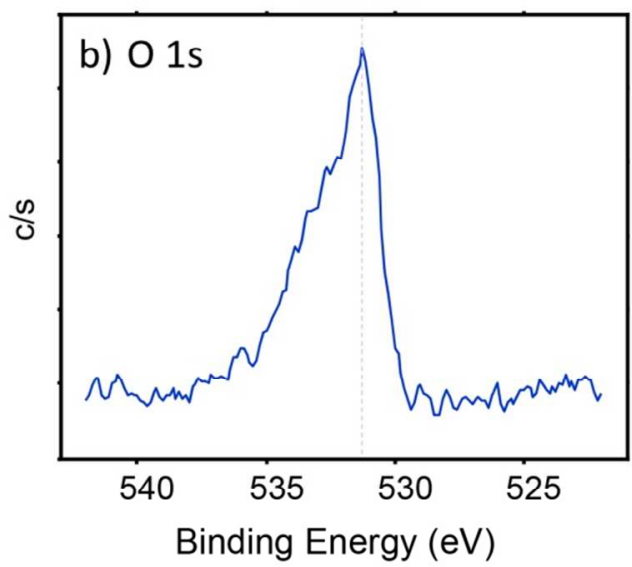

$84.1 \mathrm{eV}$

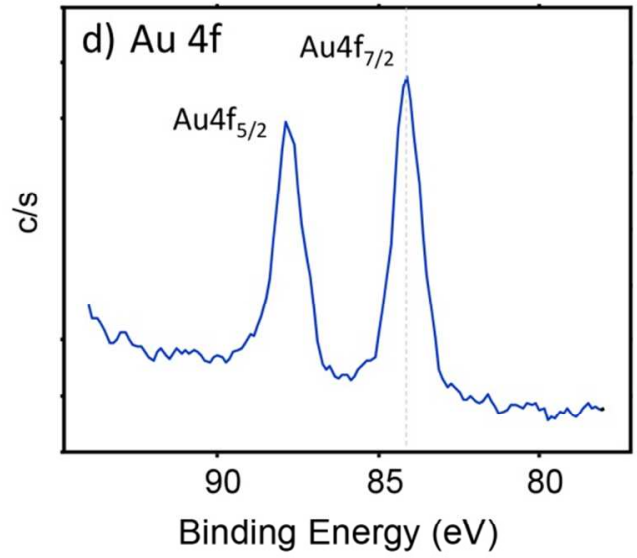

Figure S5. High-resolution spectra from the Au/Ag-core/shell nanoparticles after one wash. a) C 1s, b) O 1s, c) Ag 3d and d) Au 4f.

Information from the spectra in Figures S4 and S5 indicate that other than a small amount of adventitious carbon the Au/Ag-core/shell citrate coated nanoparticles (NPs) have no additional detectible contaminates. The $\mathrm{C}$ 1s spectrum shown in Figure S5a is similar to that found on citrate coated Au NPs shown in the supplemental material for reference [1]. The higher binding energy (BE) portions of the $C$ 1s spectrum are consistent with the amounts $\mathrm{C}=\mathrm{O}$ and $\mathrm{C}-\mathrm{O}$ species observed on citrate coated $\mathrm{Au}$ NPs, but our one wash Au/Ag-core/shell NPs show lower amounts of adventitious carbon than observed on the Au NPs. The O 1s peaks present in Figure $\mathrm{S} 5 \mathrm{~b}$ is consistent with the $\mathrm{C}=\mathrm{O}$ and $\mathrm{C}-\mathrm{O}$ species in sodium citrate, but not with $\mathrm{AgO}$ [2] or $\mathrm{Ag}_{2} \mathrm{O}$ [3]. The O1s peak from oxidized $\mathrm{Ag}$ would appear at a lower BE than the peaks present in Figure S5b. The Ag 3d peaks from oxidized Ag would also appear at slightly lower BEs than the Ag peaks present in Fig S5c. Thus, neither the O1s nor Ag 3d photoelectron peaks provide any evidence to suggest the presence of oxidized Ag on the NP surfaces.

As shown in Figure S6 on the following page, other than small shifts in the positions of shakeup satellite peaks, the Ag $3 \mathrm{~d}$ spectrum collected from the NPs is very similar in location and shape to Ag $3 \mathrm{~d}$ spectrum from a pure silver foil. The energy scale of the spectrometer is calibrated to the Au 4f7/2 and Ag 3d5/2 photoelectron peaks with measured values of 83.98 and $368.2 \mathrm{eV}$, respectively, for clean metal foils. The corresponding measurements for the Au/Ag core/shell NPs were 84.1 and $368.2 \mathrm{eV}$. Relative to the clean metal foils, the Au4f7/2 peak from the AuAg NPs appeared to be slightly shifted $0.1 \mathrm{eV}$ higher while the Ag3d5/2 peak was the same. Shifts to higher binding energies for Au NPs with diameters less than $10 \mathrm{~nm}$ have been observed previously [4, 5]. 
The spectra from the one and two wash particles are being made available for others to analyze [6]. The spectra are fully consistent with the modeled layered structure reported in the main paper.

Our analysis using SESSA has been based solely on peak area, Chudzicki et al. [7] have shown that it is possible to fit full XPS spectra using SESSA, including the background signals.

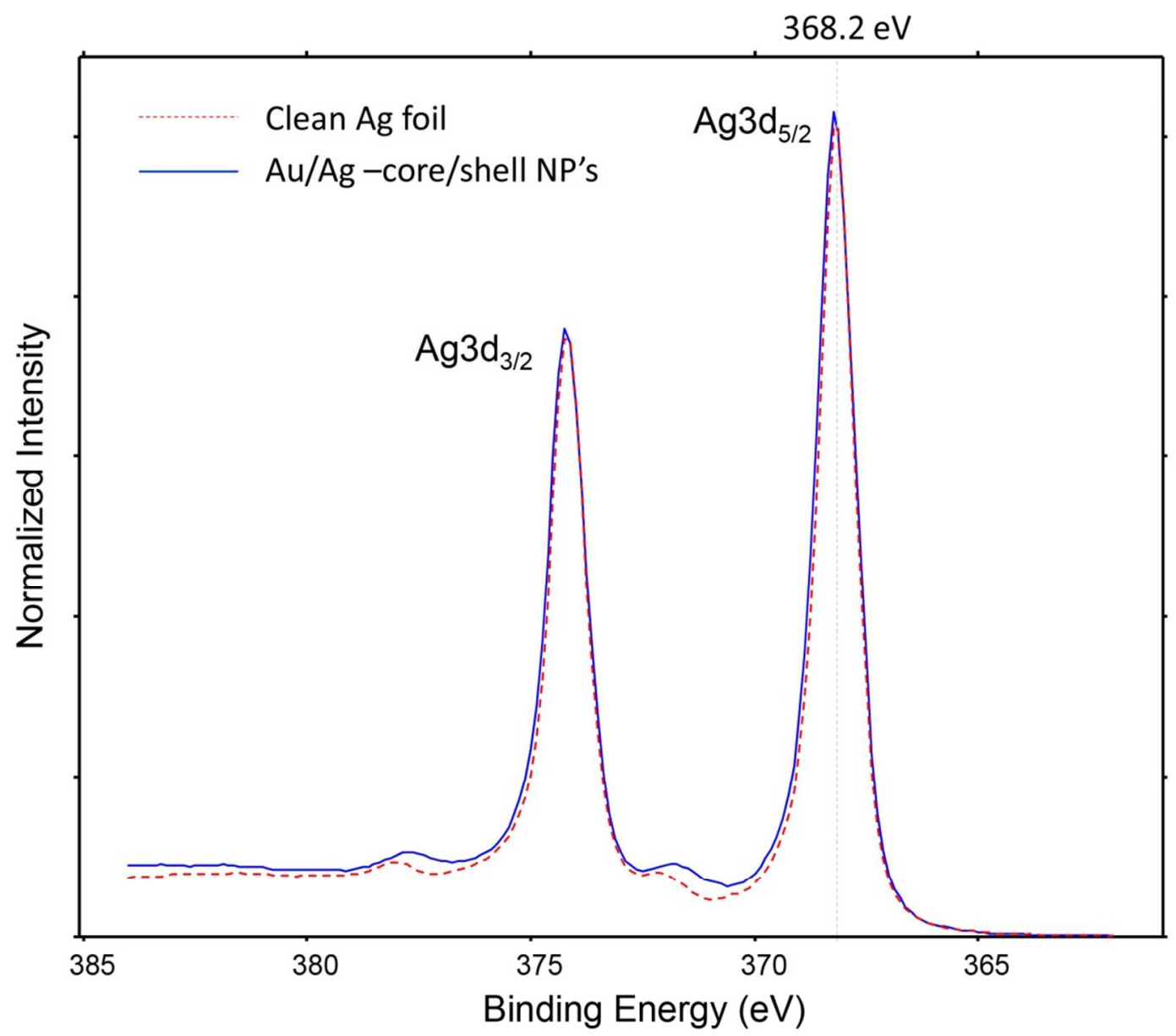

Figure S6 - Comparison of the Ag 3d photoelectron peaks from a pure Ag foil (red dashed line) and the Ag-shell Au-core nanoparticles. The binding energies of the main peaks are nearly identical, but there are differences in the positions of shakeup satellite peaks.

\section{References}

[1] J.-W. Park and J. S. Shumaker-Parry, J. Am. Chem. Soc., vol. 136, pp. 1907-1921, 2014/02/05 2014.

[2] G. B. Hoflund, J. F. Weaver, and W. S. Epling, Surf. Sci. Spectra, vol. 3, p. 163, 1994.

[3] G. B. Hoflund, J. F. Weaver, and W. S. Epling, Surf. Sci. Spectra, vol. 3, p. 157, 1994.

[4] J. A. Smith, M. Josowicz, M. Engelhard, D. R. Baer, and J. Janata, Phys. Chem. Chem. Phys., vol. 7, pp. 3619-3625, 2005.

[5] J. Radnik, C. Mohr, and P. Claus, Phys. Chem. Chem. Phys., vol. 5, pp. 172-177, 2003.

[6] M. H. Engelhard, J. N. Smith, D. R. Baer, Surf. Sci. Spectra, vol. submitted, 2016.

[7] M. Chudzicki, S. M. W. Werner, A. G. Shard, Y.-C. Wang, D. G. Castner, and J. C. Powell, "Evaluating the Internal Structure of Core-Shell Nanoparticles Using X-ray Photoelectron Intensities and Simulated Spectra," Journal of Physical Chemistry C, vol. 119, pp. 17687-17696, 2015. 
